\title{
Presentación
}

\section{De la imagen a los contextos. Sobre las maneras de abordar e interpretar la producción visual en arqueología. Segunda parte}

En este volumen presentamos la segunda serie de trabajos orientados a analizar, discutir y compartir las distintas experiencias y formas de abordar el discurso visual desplegado en diversos soportes y contextos. La primera versión de estos trabajos fue presentada en el simposio "De la imagen a los contextos. Sobre las maneras de abordar e interpretar la producción visual en arqueología", realizado en agosto de 2016, en el marco del XIX Congreso Nacional de Arqueología Argentina, celebrado en San Miguel de Tucumán.

En esta entrega se incluyen 7 artículos que abordan el análisis visual de las imágenes desplegadas en una variedad de soportes expresivos: arte rupestre, recipientes y figurinas de cerámica, estatuillas de madera, objetos de metal y calabazas.

En el primer artículo, Fiore y Acevedo aportan información actualizada sobre el arte rupestre de la localidad arqueológica Viuda Quenzana, ubicada en el extremo sur del Macizo del Deseado (Patagonia, Argentina), a partir de la relocalización de sitios previamente reportados y del registro y relevamiento de 26 sitios que fueron por primera vez identificados durante sus prospecciones en el área. En este trabajo, analizan la producción de arte rupestre en Viuda Quenzana a partir de la integración de información relacionada con los soportes rocosos, los sitios, los motivos y las técnicas de ejecución con el objetivo de evaluar el emplazamiento espacial de los motivos en los soportes y en el paisaje, su distribución y densidad, así como la variabilidad en los repertorios artísticos. Proponen un modelo de evaluación combinada que contempla la cantidad de motivos y de tipos de motivos, a fin de analizar el grado de variabilidad y de recurrencias existentes. Los resultados sugieren la existencia, en Viuda Quenzana, de una gran amplitud creativa de diseños combinada con una potente recurrencia de determinados tipos de motivo que han sido reproducidos a lo largo del tiempo.

En el segundo artículo, Lépori y Martel se proponen dar cuenta de la red de relaciones que se teje en torno a la producción del arte rupestre en Antofagasta de la Sierra (Noroeste, Argentina), durante el período de transición a la producción de alimentos (5500 a 1700 años AP). Se orientan a comprender la variación de las técnicas de producción rupestre desde una perspectiva que contemple su rol como un agente activo y necesario en el proceso de cambio abordado. Para ello analizan las tres modalidades estilísticas definidas para este lapso 
(Quebrada Seca, Río Punilla y Peñas Coloradas) enfocando las técnicas de producción, el emplazamiento y las temáticas centrales que las distinguen. Su perspectiva y análisis les permite observar que a lo largo del proceso de transición se produce una serie de cambios en el arte rupestre que incluyen la distribución espacial de los sitios, las frecuencias de utilización de las técnicas de producción, el abandono/incorporación/continuidad de determinados motivos, patrones de diseño y temáticas rupestres. Durante este lapso y a partir de la relocalización del arte rupestre en un lugar activo dentro de este gran proceso de cambios, los autores detectan el paso de un arte de producción, consumo y acceso más restringido, a un arte rupestre más público y con menos restricciones que operó como una estrategia visual que permitía dirimir y justificar el nuevo orden, apelando a representaciones menos ambiguas.

Los siguientes tres artículos enfocan el análisis de representaciones corporales desplegadas en distintos conjuntos de figurinas cerámicas y estatuillas de madera procedentes de diversos contextos.

En el primero de ellos, Pastor y Tissera abordan el análisis de los diseños de pinturas y/o tatuajes faciales que registran desplegados en un conjunto de figurinasde arcilla procedentes de la región centro de Argentinaubicadas temporalmente en el lapso ca. 1500-300 años AP y que se encuentran depositadas en colecciones museológicas o formando parte de publicaciones previas. Realizan un recorrido por el corpus de información histórica y etnográfica que señala la importancia de las imágenes plasmadas sobre el cuerpo como un medio de comunicación visual entre numerosos pueblos originarios de Sudamérica y partiendo de esta idea analizan los diseños faciales de 271 figurinas modeladas procedentes en distintas áreas. Analizan los diseños exclusivos no compartidos, el grado de estandarización del repertorio, y las vinculaciones existentes entre los diseños de las diferentes áreas. Su análisis les permite, por un lado, plantear hipótesis acerca de la configuración dual que habría definido la cosmología de estas sociedades, y, por el otro, proponer un modelo en base a dos grandes esferas de interacción, definidas por el uso excluyente de segmentos del repertorio iconográfico y por lógicas contrastantes de funcionamiento.

Por su parte, Vilas, presenta el análisis de un conjunto de figurinas cerámicas antropomorfas procedentes del Noroeste Argentino, específicamente de las Provincias de Catamarca y La Rioja. Propone una metodología que le permite estudiar sistemáticamente las representaciones corporales para identificar las formas de construir los cuerpos que circularon entre las personas que habitaron la región entre los 600 a 1000 AD. La mayoría de las piezas que analiza se encuentran fragmentadas y provienen del relevamiento de colecciones de museos y por lo tanto no cuenta con datos precisos acerca de sus contextos de recuperación y sus procedencias. Los resultados de sus análisis cuali y cuantitativos indican la existencia, por un lado, de formas compartidas de construir los cuerpos en relación a las técnicas de manufactura entre 
distintas zonas, y por el otro, de diferencias en cuanto a las formas de configurar el cuerpo e imprimirle expresividad.

El siguiente artículo también aborda las representaciones corporales, pero a partir del análisis de estatuillas antropo/zoomorfas de madera producidas en Rapa Nui y recolectadas por navegantes durante los siglos XVIII Y XIX. En este trabajo, Armstrong desarrolla una propuesta metodológica basada en la teoría queer y en enfoques relacionales a fin de indagar en las formas en las que este conjunto de 372 cuerpos en madera puede dar cuenta de las formas en las que la población rapanui pre-contacto conceptualizó sus propios cuerpos. Ninguna de las estatuillas fue hallada en contexto arqueológico, sino que se encuentran depositadas en colecciones privadas o de museos, posiblemente como resultado del intercambio entre la población rapanui y los exploradores europeos y americanos. Su análisis le indica que estos cuerpos de madera condensan una fluidez de cualidades que vuelve difícil la aplicación de categorías analíticas rígidas sobre el cuerpo y los objetos. Armstrong sostiene que estas figurinas jugaron un rol activo en la expresión y reproducción de una red ontológica en la que los cuerpos podían ser ensamblados y desensamblados. La producción de estos cuerpos de madera participó en un proceso particular de creación del mundo, vinculando de manera explícita distintos seres y manifestando la naturaleza compuesta de los cuerpos.

A continuación, el artículo de Leiva propone la primera aproximación al análisis de un tipo de soporte que cuenta con escasos abordajes sistemáticos: las calabazas decoradas. En esta oportunidad la autora analiza un conjunto de calabazas provenientes del extremo norte de Chile y ubicadas cronológicamente en el Periodo Intermedio Tardío. Durante el análisis, se caracterizan los elementos iconográficos considerando las unidades morfológicas, tipos de articulaciones y tipos de simetría desplegados en las 96 calabazas pirograbadas o incisas provenientes de dos sitios funerarios emplazados en zona de valle y costa, respectivamente. Esta propuesta de análisis visual le permite caracterizar la estructura iconográfica presente en las calabazas de ambos sitios detectando las regularidades existentes en la composición gráfica, que reflejan, según la autora, un patrón socialmente consensuado por las poblaciones que habitaron el extremo Norte de Chile ca. 1000-500 años AP.

Finalmente, el artículo de Kligmann y Falchi se orienta a identificar patrones en el modo de representación de un tipo de motivo particular: la lagartija. Para ello, analizan, a partir de una propuesta tipológica elaborada previamente, 119 imágenes de lagartijas presentes en distintos soportes de la iconografía prehispánica del NOA (cerámica, arte rupestre, metalurgia, hueso y piedra). La conformación de esta muestra resulta del relevamiento de la literatura arqueológica argentina ydel registro de algunas piezas cerámicas depositadas en colecciones museográficas. Este recorrido les permite destacar la utilidad de las tipologías para analizar grandes volúmenes de datos, encontrar patrones comunes y postular la existencia de distintos 
modos de representación de las lagartijas en los distintos períodos temporales considerados: Período Formativo, Integración Regional y Desarrollos Regionales.

Invitamos al lector a recorrer estas páginas y agradecemos nuevamente a todos los colegas que participaron a través de sus artículos, al Dr. Álvaro Martel quien fuera comentarista del simposio, a todos los evaluadores anónimos y a los editores del Boletín por ayudarnos en la tarea de concretar esta publicación.

Mara Basile*

Inés Gordillo**

* Instituto de las Culturas (IDECU)

Universidad de Buenos Aires-CONICET

Facultad de Filosofía y Letras

Museo Etnográfico J.B. Ambrosetti

* * Instituto de Arqueología

Facultad de Filosofía y Letras

Universidad de Buenos Aires 